\title{
Driving and "passengering" : notes on the ordinary organization of car travel
}




\section{AUTHORS:}

Barry Brown, Eric Laurier, Hayden Lorimer, Owain Jones, Oskar Juhlin, Allyson Noble, Mark Perry, Daniele Pica, Philippe Sormani, Ignaz Strebel, Laurel Swan, Alex S. Taylor, Laura Watts \& Alexandra Weilenmann

(Order of institutions follows order of authors)

Department of Computing Science, University of Glasgow.

Institute of Geography, University of Edinburgh.

Department of Geosciences, University of Glasgow.

Department of Geography, University of Exeter.

Interactive Institute, Stockholm.

Tri, Heriot Watt University.

Department of Computing, Brunel University.

London School of Economic.

Department of Sociology, University of Manchester.

Institute of Geography, University of Edinburgh.

Department of Computing Science, Brunel University.

Microsoft Research, Cambridge.

Department of Sociology, University of Lancaster.

IT University, Gothenberg.

Address for correspondance:

Eric Laurier, University of Edinburgh

Eric.laurier@ed.ac.uk 


\section{ABSTRACT:}

We spend ever increasing periods of our lives travelling in cars, yet quite what it is we do while travelling, aside from driving the vehicle itself, is largely overlooked. Drawing on analyses of video records of a series of quite ordinary episodes of car travel, in this findings paper we begin to document what happens during journeys. The material concentrates on situations where people are travelling together in order to examine how social units such as families or relationships such as colleagues or friends are reassembled and re-organised in the small scale spaces that are car interiors. Particular attention is paid to the forms of conversation occurring during car journeys and the manner in which they are complicated by seating and visibility arrangements. Finally the article touches upon the unusual form of hospitality which emerges in car sharing. 


\section{INTRODUCTION}

With the grand convergence and proliferation of multiple resources for and expectations of mobility, more and more of us are travelling, and making our homes in $\operatorname{cars}^{1}$ (Larsen, Urry, \& Axhausen, 2006). Yet cars are not simply devices that let us get from A to B. The morning traffic jams that congest our cities have become for many the start to their working day. We eat breakfast in our cars, phone friends, talk politics. Journeys in them are often important occasions for our everyday talk and activity. Cars are even where many teenagers go to begin love-lives beyond the parental gaze back home. Cars have, in short, become places we inhabit without necessarily being designed to be habitable.

If we rely on simply charting the increases in mobility and car use, or lamenting the environmental cost, we will miss the reconfiguration of many familiar social formations into the car (Pica, Sorenson, \& Allen, 2004). Perhaps because the car has become emblematic of the mass produced object (Urry, 1999, 2000), the root noun of Fordism, we assume that as society briefly manifests itself there it is a uniform unchanging unit of transportation, cryogenically suspended as it passed from A to B. This paper takes the lead of a number of theorists of speed and mobility who have turned this notion around and placed movement at the heart of how our societies and cultures are organised (Cresswell, 2006; Urry, 2000). In our project we have been interested in following the ambitious routes laid out by Cresswell and Urry: re-specifying what have tended to become overly abstract theories and models of transportation.

This article explore how it is that cars have become 'habitable' for us in our everyday activity $^{3}$. Using visual records of passengers and rivers we explore and document how it is that cars have become a crucial part of our everyday lives (Brown, Green, \& Harper, 2002; Perry \& Brodie, 2005 ; Thrift, 2004; Urry, 2002). We examine a straightforward question: what do we do in cars, and how do we do it? The intention of this article, then, is to swivel around academic armchairs so as to better view the backseat of the family car in all its banana-skinned, half-empty drink carton glory, and better attune ears to Wogan in the morning rush hour as a queue begins to back up on the sliproad.

In our project we have deliberately considered situations where people travel in cars together, or to give it a more praxiological ring, as 'a together'. At one level, it is because the one-person-one-car mode of travelling is so immensely wasteful of resources, and thus environmentally harmful, that we choose to look towards those who more or less successfully manage their vehicle use collectively. Our use of the unfamiliar term 'collective private transport' gathers together the disparate situations where a number of people - be they friends, families, acquaintances or colleagues - find themselves sharing a vehicle more, or less, informally. We use the term to mark out a terrain that lies between the usual contrast between 'public transport' and 'private transport'. We would have preferred to talk of 'car sharing' except that this phrase has become associated with formalised share schemes (which are nonetheless one of the instances to which we refer).

\footnotetext{
${ }^{1}$ Note though that we are not, on average spending more time travelling per day than we did before. It is our mode of travel that is changing. We walk much less, we cycle less, we boat less, we bus less, we train less and horse, almost not at all.

${ }^{3}$ More details on 'Habitable Cars: the organisation of collective private transport' at http://web.ges.gla.ac.uk/ elaurier/Habitable_Cars/
} 
This definition, of social groups on the basis of vehicles, lets us explore collective entities the respective vehicles accountably organise.

\section{Studying the Car}

As Miller remarks, the car is a surprising absence in our discussions of the social though Miller's (2001) own edited collection alongside Thrift \& Urry's (2005) wide-ranging theme issue and book have made substantial inroads. Indeed, there have been several recent studies of the relationship between the city and the car, notably (Sheller \& Urry, 2003), the family and the car (Sheller, 2005) and inequality and the car (Shove, 2003). Drawing on actor-network theory, new hydrids of car and humans create new forms of emotional agency (Michael, 1998, 2000). The particularities and transformations of listening to music in the car have been studied by Bull (2005). Historical documentation of the gradual emergence of the motorway as a distinctive place requiring new codes of conduct has been examined through a Foucauldian lens (Merriman, 2006). Moreover there is growing body of ethnographies of the road (Appleyard, Lynch, \& Myer, 1964; Juhlin, 2005; K. Lynch, 1960; Venturi, 1988; Watson, 1999) and of transport and mobility more generally (Cresswell, 2006; Watts, 2005; Weilenmann, 2003). Yet we find that the interior of the car remains a largely unexamined space, which is hardly surprising given the practicalities of doing ethnographic fieldwork there (one of the rare examples is Katz, 1999). Of course, the fields of transport geography, economics, road policy, environmental science and the like have all taken the outside of the car as an important topic - or more specifically it's movements and infrastructures. The inside, however, is perhaps almost too trivial, as a space not of state, city and politics but one of handbags, refreshments and gossip.

Indeed, a constitutive feature of the phenomenon we have chosen to investigate is the generally unremarkable, anything but noteworthy, character of our ways of speaking about and during the routine activities of travelling together in the car (unless practical problems arise). It may or must sound odd to topicalise this in an article. That is, mundane, ordinary, down-to-earth, everyday activities under headings such as 'doing driving', 'doing passengering' or 'doing conversation' in traffic, the 'enormous work' it takes to do so, and so on (Harvey Sacks, 1984). However, what we are proposing to attempt is to integrate the analysis of talk with the description of the phenomenon; that is, the collective achievement of members of traffic cohorts and how analysts at source and afterwards go about formulating, when and how it occurs, as a locally available, socially organised fact (Bjelic, 2004; Garfinkel, 2002; M. Lynch, 1993). Our focus on its 'local availability' is a hopeful reminder of the occasioned settings in which traffic talk, its variability or uniformity, makes sense - in commonsensical terms at least (e.g. in a driving lesson, stuck in a traffic jam). That is to say, the outside doesn't happen without the inside: with the local organisation and activity of the car, the concerns of those who take seriously transport, disappear.

An important question thus arises: does the idea of 'talking traffic', or for that matter 'talk in traffic', make much sense in an academic setting rather than having just driven to one? From an ethnomethodological perspective, driven to naturalist perfection, it makes perfect sense. Indeed, a recent radical field of topical inquiry has arisen from the relationship between traffic and traffic talk: mobility studies. For many, naturalistic description generates a curious cluelessness as to why would want to do such work. Of course, there are a number of reasons for doing studies of naturally organized ordinary activities, spelt out by others elsewhere (Livingston, 1987; Michael Lynch, 2002; Watson, 
1999). Very briefly, they return us to matters of research concern, but re-specified by the ordinary. Matters of daily concern otherwise overlooked because we are immersed in their familiar, routine and trustworthy appearances. Studies of how mundane car travel is locally accomplished provide descriptions that re-familiarise us with the centrality of the unremarkable and indispensable. As we return to in the conclusion, the relationship between cars and traffic is especially perspicuous for examining the manner in which we can become confused by 'macro' and 'micro' (Latour \& Callon, 1981). Our descriptions of what goes on in the micro space of the car interior are intertwined with what is occurring on the macro road system. There is no point on which to pivot and divide the macro from the micro. In that memorable phrase, it's turtles all the way down.

\section{Group Analysis of Video Data}

For a piece of research rooted in the social sciences this paper is unusual in that its authors could notionally number fourteen. The analytic event and chosen method offer some explanation for such a large number of contributors. The authors worked closely with others in three groups on twenty four video clips of between two and five minutes in length from a corpus recorded in six different vehicles with varying passengers. The clips were analysed in three two-hour sessions and could have been analysed for much longer. The analysts came from a variety of backgrounds in social, cultural and technological research. What the video corpus provided was more than a common point of reference, it supplied a point of return to balance our academic desire to find points of departure. As such we kept returning to the video footage to remind us what had actually happened during particular episodes of travelling together in the car (Heath, 1997). Much like a careful reading of novel advertisement or film, we viewed, and repeatedly reviewed, each clip doing our best to describe what was happening there for those at the time, and for us as analysts.

The paper's findings are presented under seven headings namely, driving together; the distinctiveness of talk-in-cars; slow conversation in a fast car; the place of family play, learning and dispute; the vehicle as a visibility device; the hospitality of car sharers; and the journey as a unit. This suite of studies of aspects of automobility is not intended as a rigid typology for car sharing. There are, after all, many more besides (Balch, 2005). Rather it represents those instances of car habitation that our noticings, observations and preliminary analyses condensed around. In future papers we intend to deepen the analysis particular topics that here are presented as a collection of emerging themes. Our hope is that while we lose much in the overview we never the less offer glimpses of how we actually travel on the UKs roads and how various activities of non-transportational kind are undertaken there (Lyons \& Urry, 2005; Mondada, 2004; Watts, 2005).

Through presenting these seven themes we hope to open up and describe common car situations - elements of what happens and how it happens during car journeys. Of course, our interest is not only in these themes and situations - we want to reflect on what they could tell us about collective private travel. As such understanding even one situation in the car is of worth, whatever the generality of those findings. For many, who like to jump quickly from the fragment to the whole of mobile society, we ask for some patience; and the acknowledgement that the whole is always made from parts that never quite fit together. We ask that the reader be sensitive to, not just the generalities, but the 
routes marked out by our fragments. We do not claim to provide an overview or total explanation of automobility, but we do hope to offer insights that are sometimes reminders and sometimes novel findings. 


\section{Analysis}

\section{Driving Together}

In contrast to the idea of the car driver as the individual consciousness - a 'ghost in the machine' (Ryle, 1949) - who looks out at the passing 'environment' (Watson, 1999) we found plentiful incidences of 'driving together' where front-seat passenger and driver were conjoined in their engagement with the road ahead. While we might want to assume the passenger is passive this is, by and large, far from true. A concept like the "back-seat driver" shows that there is an idea of the passengers not always being passive in the car, and that their participation in driving can be morally dicey. At various junctures and junctions, front-seat passengers display and account for their awareness of the car's relative position within evolving traffic formations, and of the driver's previous, current, and likely future, actions. Equally, drivers show awareness of their passenger's awareness, assistance, obstruction and evaluation of their (and other's) driving. And as in the example below bring road conditions to their passenger's notice.

\section{Figure 1}

Driver: Where's all the traffic? a barbecue

Passenger: You have a valid point ((looks around)) Good sunny weather let's go home and have

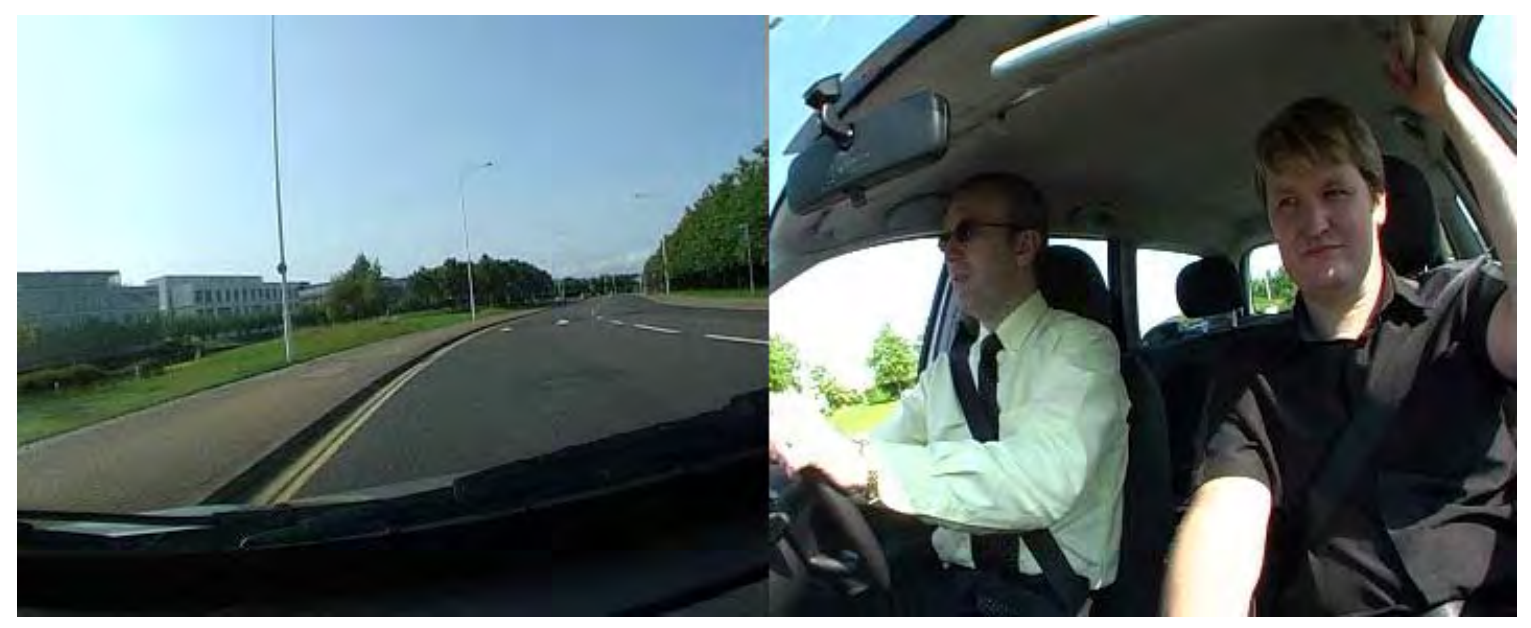

In the video clips, there were numerous incidences of front (and, less often, back seat) passengers responding to the traffic: looking sideways at traffic lights, showing alarm on their face or through their tensing body when other vehicles brake suddenly, commenting on the busyness and quietness of the roads. Although passengers expect the driver to get them from A to B comfortably and safely, unlike train carriage passengers they can, and do, become involved in the demands of driving the vehicle. In particular circumstances, and to execute certain challenging manoeuvres, drivers call on, or are offered by, the passenger, help in navigating, identifying and monitoring the proximity of obstacles (Laurier, 2005). Passengers assist in retrieving things from the interior of the car such as mobile phones, CDs, maps, documents, food and water, clothing and more. In response to incidents on the road, solicited by the driver or otherwise, passengers evaluate the actions, or intentions, of other drivers and their vehicles. In response to the 
driver's mood or energy we found passengers re-assuring them, calming them down or helping keep them alert.

Given that the driver and front-seat passenger experience jointly the traffic conditions encountered, that the passenger watches over the driver, does her bidding when requested and that they work together at various stages of the journey, arriving at a destination is a shared accomplishment. This leads us to redefine, in various ways, what car-sharing might involve, since in many ways the front-seat passenger becomes part of the 'crew' that drive the vehicle. To share the vehicle as a passenger is to become partly responsible for its driving and partly responsible for its driver. Passenger

accomplishments in getting the car from $\mathrm{A}$ to $\mathrm{B}$ are not equal to those of the driver, of course, since the passenger only assists from time to time and backseat passengers hardly at all. The passenger can be called to account - "why did you not tell me I was going the wrong way" or equally in a tense voice "yes I had seen the car jumping the light". In studying various aspects of car transport what the passenger contributes remains overlooked by researchers with some notable exceptions (Ulleberg, 2004) even through it is frequently recognised by ourselves as drivers.

\section{The distinctiveness of talk-in-cars}

Alongside the activity of driving, cars are places of talk. What is remarkable about in the video data is how little extended silence there is, there are plenty of pauses and short silences, an issue we will return to later. In the videos of shared private transport we find an avalanche of talk on a slew of topics. This variety led us to formulate the question: is there anything distinctive about the way car travellers find their conversational topics? We are not sure whether we can confidently answer this slightly odd question, though the talk that happens in the car certainly offers us some material to work with. In fact it may not be that the topics are specific to the car but our way of getting to them, dealing with them and finishing them might well be.

By way of its bringing us into close proximity with others, the car provides a perspicuous setting where people have to look for something (else) to talk about or else sit in silence. Consider one incident in which a mother and grandmother (her mother-in-law) occupy the front seats of the car (see fig 2). They struggle to identify things in common to talk about. There are long uncomfortable silences; or at least it seemed so to us as viewers of the video-clip. Up-front, with little to say to each other, it is the children seated in the back who they listen to. From time to time, the children's chatter provides topics of conversation for the "in-laws", and the children's squabbling provides occasions for their collaboration (or not) in keeping control.

Fig 2

Son: $\quad$ And people were doing songs about dinosaurs and I got to be a steggasaw, I be a triceratops

Mum: $\quad$ ((smiling)) were you? That's a very long word for a little boy 
Grandmother: Oh gosh what's that tricer...

Mum: $\quad$ Triceratops

Grandmother: Gosh

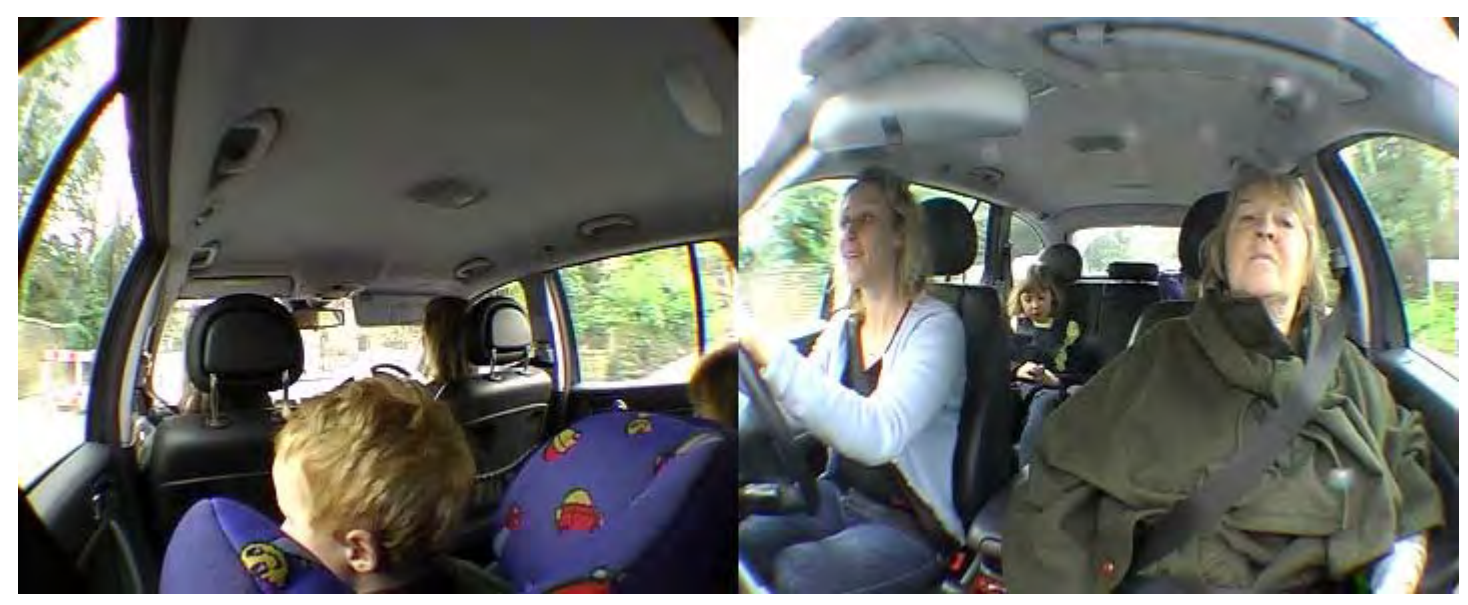

Alternatively, consider two office colleagues who keep falling into long silences en route to work. Opening greetings and queries as to 'how you are today' initiate news delivery sequences (Maynard, 2003) which will get them sometimes as far as fifteen minutes into their journey. Eventually silences arrive and it is Terry Wogan's easy-natured banter that fills the silence and eventually helps them out of it. The Radio 2 presenter's daily provision of national news, jokes, music and more provides a rich seam of topics for them to pick up and chew over. Or, consider how driving-in-traffic is one activity specific to the car that in itself initiates topics. The exercise of driving creates possibilities for talk about other cars and what they are doing, the daily appearance of traffic levels ('quiet today' (see figure 1), recollection of past events on the road ('a guy almost hit me yesterday') and what happened and is happening to those present at that time, collectively as a car. As Sacks (H. Sacks, 1992) points out, we are ever attendant to local resources which can be brought into conversation or indeed, should (or should not) be brought into conversation at risk of causing offence.

Rather like the telephone, although there is no predefined arrangement for what can be talked about, there are expectations about how we go about organising talk in the car (Hopper, 1992; Schegloff \& Sacks, 1973). While the telephone ordinarily connects just two persons at a time, in the car there can be three, four, five or more. In the arrangement of who sits where, beside whom and with their back to whom, expectations are produced of who will talk to whom. Without committing to a view of the physical structure of the car as deterministic or causative, our video clips highlighted the ongoing significance of the spatial arrangement of speakers and listeners. There are two features which Mondada (2004) alerts us to: first, rather than being arranged face-to-face, in the car we sit side-by-side and front-to-back, second, the lack of movement available to those in conversation. Picking up on the latter, the car's internal immobility is in contrast to the relative mobility of speakers inside houses and flats as they move around a room (getting up from the dinner table to bring food over) and from room to room (from hall into the kitchen where the other speaker is in the kitchen) (Mondada, forthcoming). In the car you cannot walk away from nor walk into a conversation with another speaker. The person you are in the front seat with is almost inescapably the person you are paired 
with, an issue with consequences that we return to later in the article. For some of the drivers the rear-view mirror becomes a device for monitoring back of the car becomes a key actor. In the car, co-occupants must find and deploy particular methods, in terms of taking turns, stopping and starting topics, speaker selection and so on, that deal with this unusual and fixed arrangement of speakers' bodies.

Backseat speakers commonly lean forward and into the gap between the frontseat speakers to launch or participate in conversations with them. The closing of a conversation was often marked by returning to their previous relaxed seating position in the front. For their part front seat speakers would turn their head without actually attempting to secure eye contact with backseat speakers in ways that indicated listening, agreeing or otherwise participating in the conversation. Initiating or re-initiating conversations as often began with some sort of shuffling and a clearing of the throat.

Having made these brief observations we would want to be cautious about comparing the car as a communication setting with an otherwise generalised notion of face-to-face conversation. The car is one particular framing of talking together amongst many others (such as the telephone mentioned above) which will also have their social and material framings. What makes this framing of significance is not that is a particular instance of a general model, rather the car has become a conversational space that we can generalise to and from, due to its relatively uniform design.

\section{Slow conversation inside the fast car}

In relation to other road users, the car provides an audibly sealed and publicly visible space. Conversations are thus a particular arrangement of public and private; certainly when contrasted with a café, for instance. Compare, then, the commute in the car, with the café where you go to meet someone. The purpose of the café meeting is to talk with that person, to have that occasion of being with someone. The point of the commute is notionally getting there, so if the conversation is good that is a bonus. Yet it is not quite so, since dull or stilted conversation one a one-off basis is acceptable, the repetition of the commute means that it poses a greater threat there than elsewhere.

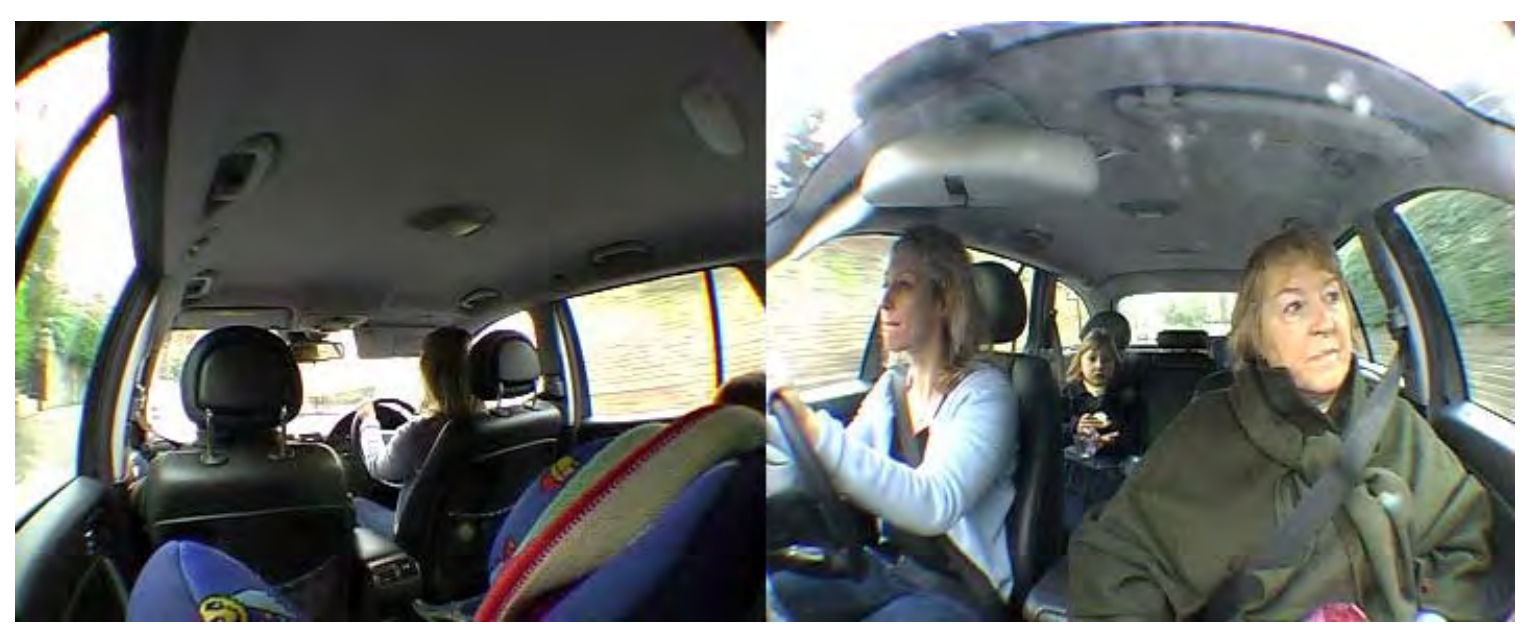

Figure 2 - 
After three minutes of silence. The grandmother looks out of her passenger window, opens her mouth, bu then says nothing. She looks again. This time she says "isn't that the house you once thought of buying?"

In the video clips, long silences among car co-occupants are a common feature of shared travel. Sometimes the silences emerged between a driver and passenger, others occur in a car with three, four or five people present. While it may seem odd to those who would say that a silence is merely the absence of conversation or more profoundly that silence is beyond language, silences are analysable phenomena and are analysed by those who hear them at the time (as well us by us afterwards) (Michael Lynch, 1999). Needless to say, there are significant challenges for researchers in terms of how analysis of silences in the car is undertaken.

Silences can be considered, variously: 'comfortable', 'uncomfortable', 'tense', or displaying attentive listening to the radio. Silences can be 'short', 'long', 'ambiguous' 'preoccupied' (e.g. the driver says nothing for the journey) or emerge specific to a topic (where small talk is continued but the most pressing subject is left unspoken). Analysis of a silence can be informed by what is known already of the car co-occupants, by events on the road that have only just happened, by conversational topics that preceded silence, by their timing with a particular song on the radio, and more. Evidently much can be imputed to silence. But even though silence is mutually sensible, it is not necessarily mutually understood, nor agreeably produced.

Instead of thinking only in terms of silence, it is instructive to consider the pausefullness, and slowness, of car conversation. The long pauses taken between turns at talk is an unremarkable and ordinary feature of conversations in the car. Just like driving, looking at landscape, listening to the radio or chattering children in the back, silence is available to those present as a 'safety net' to fall back on. When silences emerge as pauses within talk then they can be a feature of "difficult" conversation, and notably car travel is an occasion enabling conversations on very serious topics. That is, the car becomes a good place for certain sorts of conversations: the very kind that might generate pauses, need pauses, and yet want those pauses not to become too uncomfortable. By way of comparison, think of how Freud sat with his back to his patients, or of the importance of walking for certain kinds of slow, contemplative conversing. On long car journeys, the physical confines of the setting are thus a useful place to raise difficult issues. Individuals cannot walk away from the conversation, and the stretched out silence that the car enables allows for slow and considered responses to complex or difficult issues.

Compared to a telephone conversation, car-bound intimates and strangers can leave long gaps and take extended and broken-up turns, to tell their troubles and tell stories, and tell troubles as stories. For work-mates on their way home from work, the car is a place where they are allowed to launch into confessionals as well as voice complaints about other colleagues. There may be different relations here between a complainant giving vent to frustrations at the end of a long stressful day, and a complaint made on the journey to work. In this way travelling toward a day's work or travelling away from it can alter the acceptability and accountability of what is told.

\section{A small place of family play, dispute and learning}

Among parents, the car is recognised as a good place to talk to children because you have their fullest - though perhaps not undivided - attention (Taylor \& Swan, 2005). 
The reverse of this arrangement holds for children, the car is a good place to talk to parents. With no one else there to distract them they get time with mum as mum, dad as dad, whereas in other settings they might be competing with, say, mum-as-friend-tosomeone-else, dad-as-cook, dad-as-TV watcher or mum-as-homeworker. Even so, in the car children have to deal with their parent's responsibility to driving and perhaps holding a conversation with a front seat passenger. Children's desire to occupy the front seat is thus all the more understandable, since in this position you have fullest access to the captive parent (carer or grandparent). When they do win their way into the front seat it is noticeable in all our clips of young families how the children use their access to ask questions, make pleas, tell troubles, recollect events, describe objects, plot stories and more. As much as they are answering questions, handling pleas, hearing troubles parents in the front are instructing their children in how to form their questions properly, plead for things (e.g. a family dog, a new toy), explain why teacher told them off and so on.

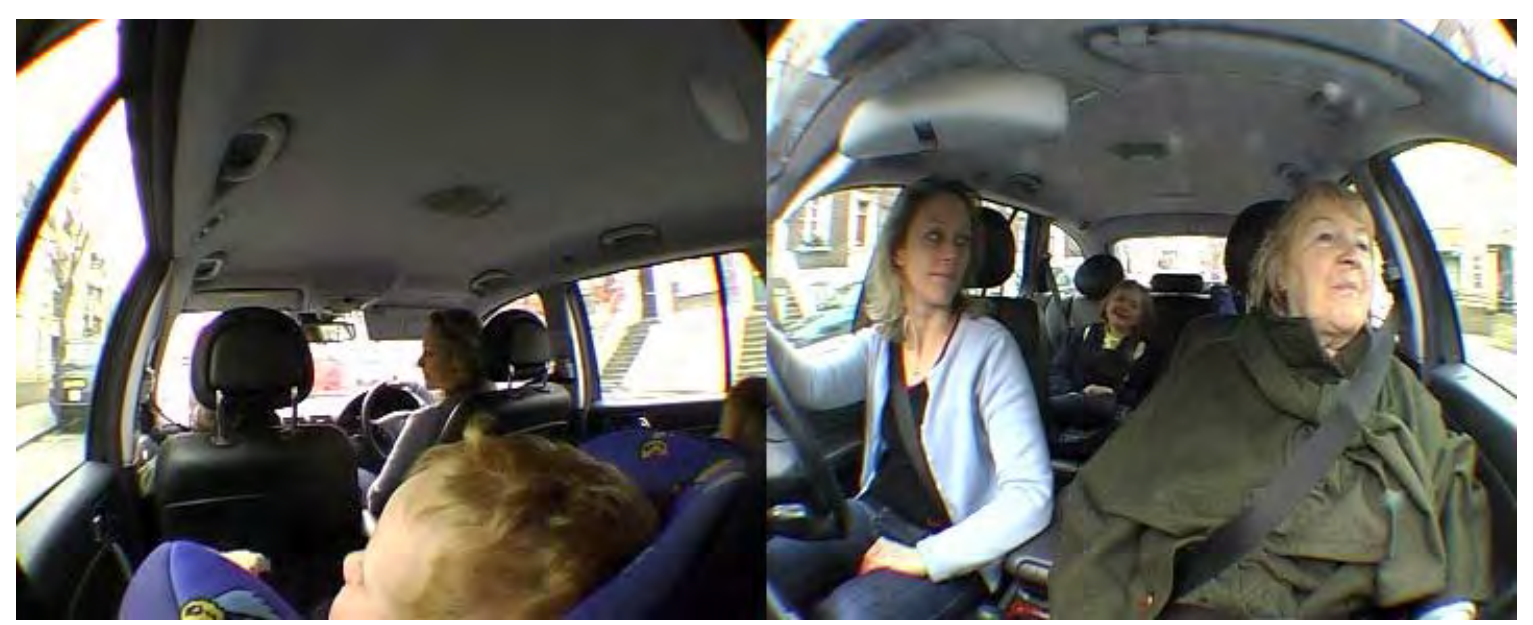

Figure 3:

Boy: I'm BIG

Girl: You're little

Boy: I'm BIG

Girl: You're little

Gran: [Shoosh-shoosh-shoosh]

$+$

Boy: [I'm big]

Girl: [you're little]

$+$

Gran [Darlings, darlings]

Boy: I'm BIG (louder)

Mum:

[>Shoosh::.:...:.:.: $<]$

$+$

Girl: You're not a big brother to me. I'm bigger than you [aren't I] 
Mum: Gracie's older than you my love

Boy: ((indec)) and I'm big

Mum: But you're big for your age darling. Yes you're nice and tall. You're perfectly big for a three and a balf year old, it's just that Gracie's six.

As we can see from the transcript accompanying figure 3 being consigned to the back seats does not preclude children from securing front seat attention. As we have noted earlier the front seat adults are sometimes listening-in and sometimes not, so quite when attention is being paid becomes harder to recognise. In the video clips a common pattern once the children in the backseat have attracted the attention of adults in the front seat is to become more and more boisterous. In the transcript above, the youngest boy present claims that he is a "big" brother to his elder sister, who is sitting alongside him. Their grandmother, the passenger in the front is listening, and laughs (Figure 6). Aware of her laughter, both children sit up and the disagreement over big/little brother status becomes more animated. As their dispute escalates rapidly, the grandmother steps in with a "shushing" noise, before ultimately the mum-driver intervenes in the argument between the children. She settles the argument with remarkable calm. There is, we are only too aware, a familiarised routine in these outbreaks of rowdiness from young children in the back seats. A little bit of attention, once secured, leads to a performance which ordinarily ends with some form of ordering, calming down, reprimanding or telling off. Then relative quiet returns, at least for a while. What we should not forget is that there are opportunities here, the children are both developing their skills of argumentation whilst also being instructed by their parents in the grammar of various concepts. In the example above, of why, although the boy is 'big' for his age, that does not make him his sister's 'big brother.'

If the family is considered as one of the primary formats for organising what happens in the car, arrangements for two (or more) families travelling together present an intriguing variation on the theme. Mixtures of parents, grandparents, children and family friends create situations where non-family adults sometimes are expected to deal with the actions of other people's children. In such situations, how non-family members deal with someone else's son or daughter in the car is a sensitive matter for al parties, children, parents and other adults. Several video fragments of two mums travelling together (see figure 4) with their respective children are revealing. Friends of family intervened at particular points and in particular ways in situations originating with children other than their own. Non-intervention is one option. Their status as grandparents or friends and not the parents is an easy solution in the sense that responsibility can be deferred and devolved, as it is primarily the mother's (or father's) moral responsibility to keep their children in check (at least in most Western cultures). Even so, failing to monitor the shift from harmless bickering to a serious falling-out begins to display a distinct lack of support for their friend-as-parent or their-daughter(in-law)-as-parent. This previous compound noun is hyphened together in order mark the complexities of moral responsibility alongside the realisable rights to intervene in such a situation. 


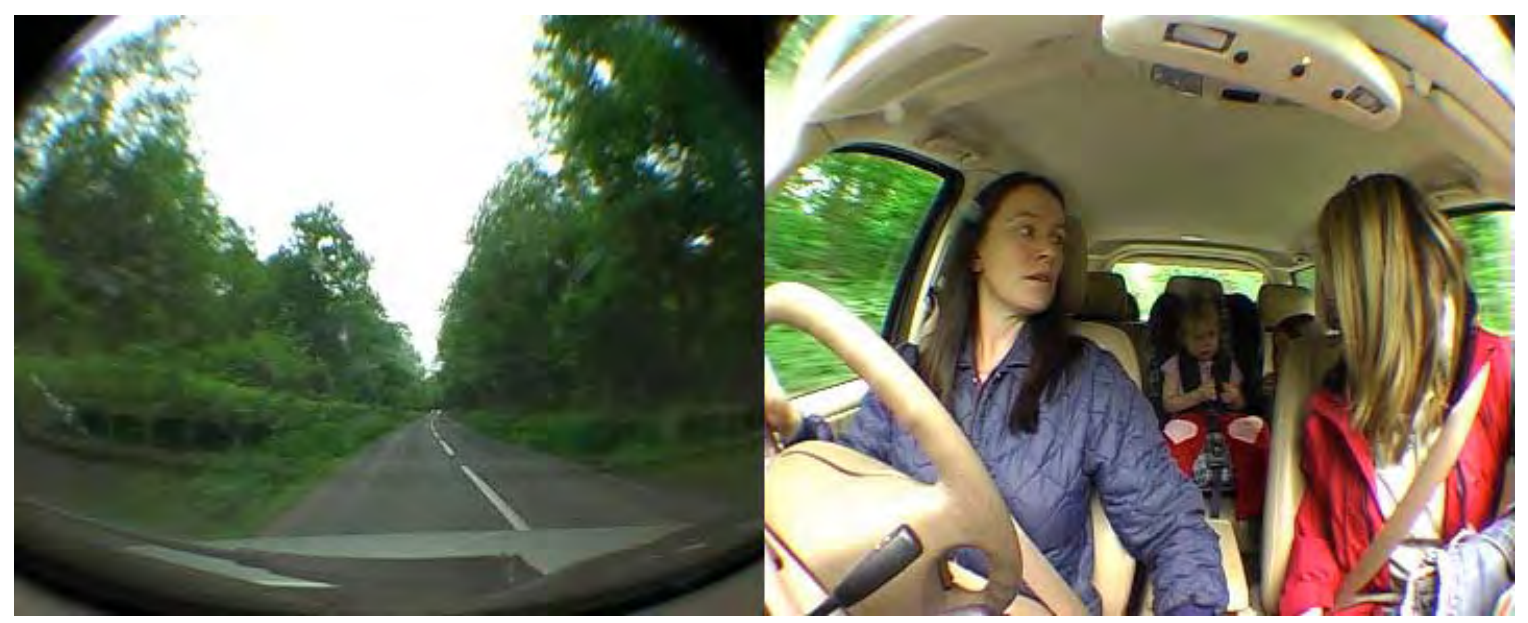

Figure 4

Anna: MUM. MUM. Alice's got this yellow pus stuff coming out of her eye

((Mum_left looks up into rear view mirror))

ML: Yes I know she's got conjunctivitis so don't touch it please cause it's very contagious::

Anna: Okay

((Mum_right looks over shoulder into back----------------------))

ML: And you need to wash well you need to wash your hands

MR: ((still looking back)) Yeah you need to/

((ML now looks toward MR $)$ )

((Alice meantime takes her hand away from her eye and rubs her other hand)) $+$

MR: Alice don't, don't touch you other eye because it will spread to the other eye as well darling. So just wait till you get home so you can wash your hands okay:::

((Alice now touches her eye with her other hand))

ML: And you Anna, keep your eyes away from your face poppet.

((Alice now touches eye with first hand again $))$

Anna: Okay

ML: Goodgirl

Morally speaking, someone ought to stop the little girl with conjunctivitis from spreading it to her other eye or the other children and if the non-parent chooses to do so herself then she has to design her move in an appropriate manner that does not supplant the mother's primary responsibility. Nor should her intervention end up as, inferentially, a criticism of the other's parenting. Yet at the same time the intervention has to be 
something recognisable as such to the children in the back. What we witnessed earlier was a solution such as a "shushing" that is suitably designed so as to be heard by the children as a mild reprimand and by the other mother as a cue to her that more serious intervention might be required. Moreover, "shushing" in relation to more extended spoken reprimands, is an action likely to be judged as help rather than interference. This time we have the mother who is the passenger doing what the mother who is the driver cannot do, turning around to more closely monitor what is happening in the back. Her close monitoring shoring up her being the appropriate one to see exactly what Alice is up to with her pus-ridden eye.

Thus, cars are a setting for agreements and disputes over how a family works between family members and for others who travel with them. It is the very recurrency of similar situations in the car that makes them central to the ways in which hierarchies are reestablished, rivalries emerge and are (sometimes) resolved, and explanations given for what children are allowed to do according to age, gender, illness and so on. In trying to settle disputes, parents instruct their children in the logical organisation of that fundamental social form, 'family'. They do so according to occasioned distinctions made between age, gender, what siblings should do for each other, what parents should do for children and vice versa. Simultaneously learning when and how to make relevant and use those distinctions is inseparably part of the lesson, and one about a much finer tuning than simply in the car or not in the car. And, of course, children learn about how a family should travel as a collective: from the simplicities of instructions for 'putting your seat belt on' to the pacing of toilet stops and snacking, choice of music to play, or sitting without bothering the person beside you. The car then is not simply a place for children to argue, get bored, or be transported from a-to-b, the car is a place for them to learn rules and rights, and how to use, bend, avoid, supplant or break them.

\section{The vebicle as visibility device}

The car functions as a visibility device that makes certain groups recognisable to those who are looking in from outside and to those gathered together inside. Even with a still image, from a quick glance we tell ourselves what we see: 'a family' (fig 1), 'commuters' (fig 5). 


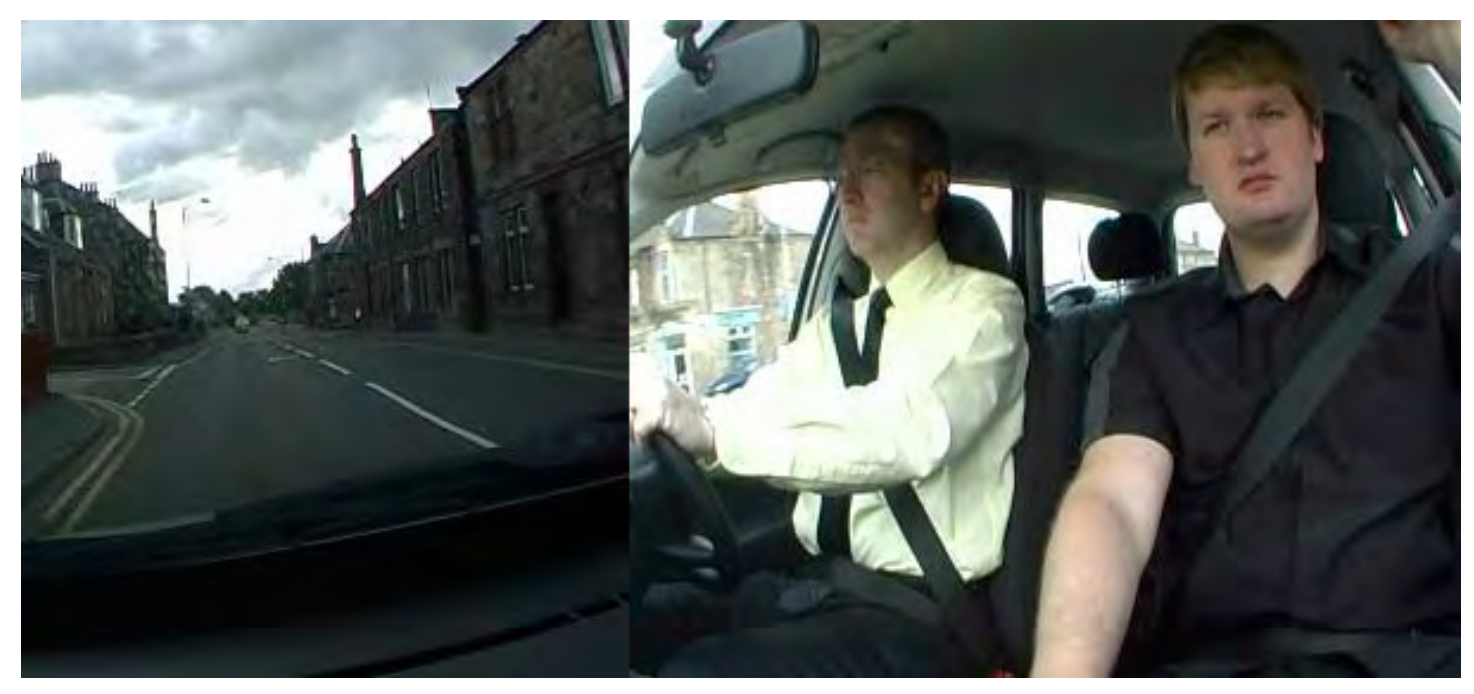

Figure 5

In such apparently easy recognition, there are social typologies and categories being put to work (Hester \& Francis, 2003). Think of observing others as they travel on the motorway. We look across at passing vehicles and their occupants and see 'a family', 'a couple'. Or, on witnessing a minor accident or example of 'road rage' we may attribute more morally consequential categorisations such as a 'boy racer' or 'Sunday driver' (Katz, 1999). The car displays co-occupants as a unit 'together' in a way that is quite distinct from a bus or a train or even pedestrians on a pavement (Hester \& Francis, 2003; Ryave \& Schenkein, 1974). Indeed we may reasonably assume that there is a relationship other than that of co-travellers in the car.

This is how, in Figure 1, viewers of even the still image quite likely arrive at the conclusion that what can be seen are two women, a grandmother (in the passenger seat) and a mother (driving). Inferring justifiably that the two people in the back are the children of the woman driving. When and if the category, 'family', is applied it collects these individuals together for the viewer (be they looking into the car from another vehicle or from this article). As a collection of persons in one car of easily discernable ages they form a gestalt - with relations of mother-daughter, grandmother-granddaughter and so on. Where a gestalt produces a set of analysable relations greater than the sum of the individuals visible in the car. Of course, it could be that that is not what we find in the car at all. They might prove to be two social workers with two children in their care. Or a woman collecting her friend's children while also giving her colleague a lift. Given that we are interested in praxiologies of seeing which are interwoven with devices that make society visible, what is of interest in the car is not so much the correctness of any categorisation of the group seen in it, rather it is how this visual analysis of car occupants is so routinely accomplished. Mundanely, we have some awareness of this - the uncomfortable feeling when mistaken with a female friend for husband and wife, or being the parent of a child we are supervising as our own.

There is more to be said of the car as a visibility device that allows viewers of a car to slot its occupants into particular categories. In Figure 1 and Figure 5 respectively, the mother and grandmother, and the two commuters appear to be looking away from each other, and never directly at each other. Leaving aside the slight distortion of perspective that is created by semi-fish eye lenses, the mutual monitoring of faces in car-based 
conversations cannot quite happen in the same way it would over a dinner table, or standing talking in the local park. The side-by-side arrangement established by the car's layout requires a different way of organising how co-occupants show each other that they are listening or not listening, use gestures for taking a turn to talk or listen, and so on (see figure 6).

Figure 6

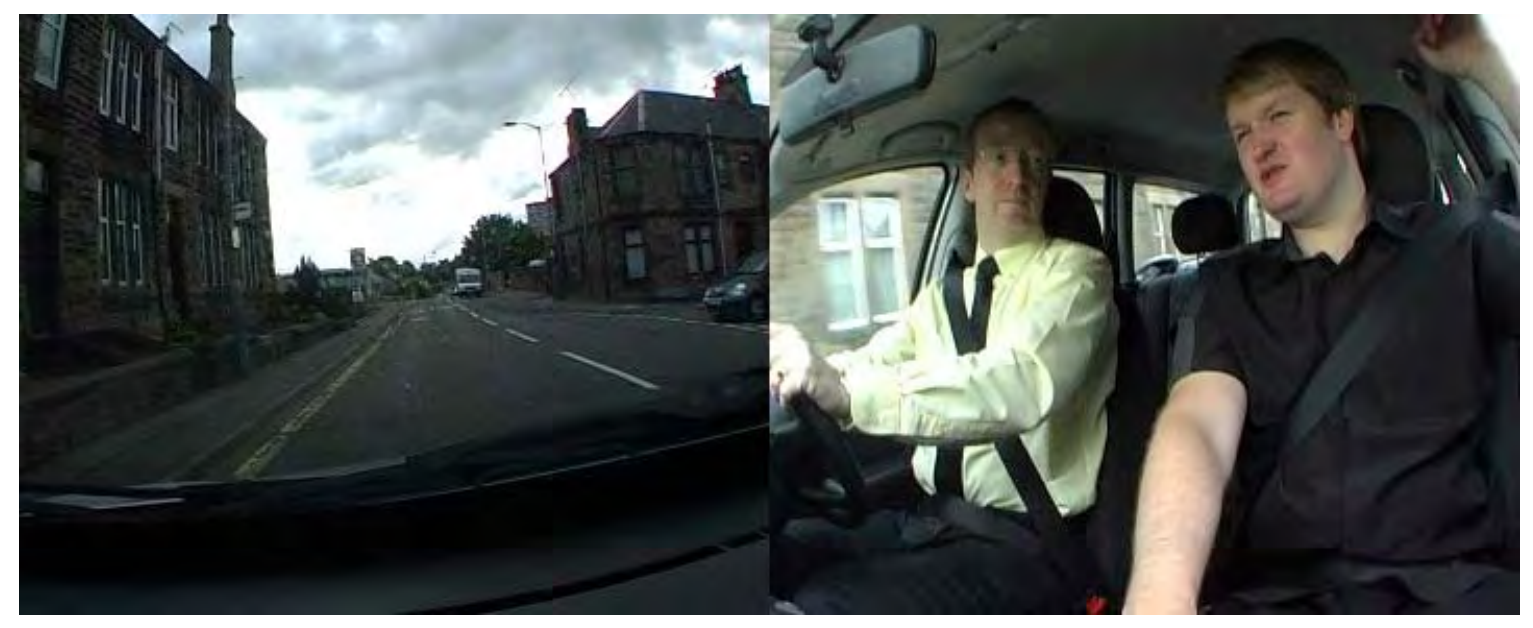

Passenger "See that proposal"

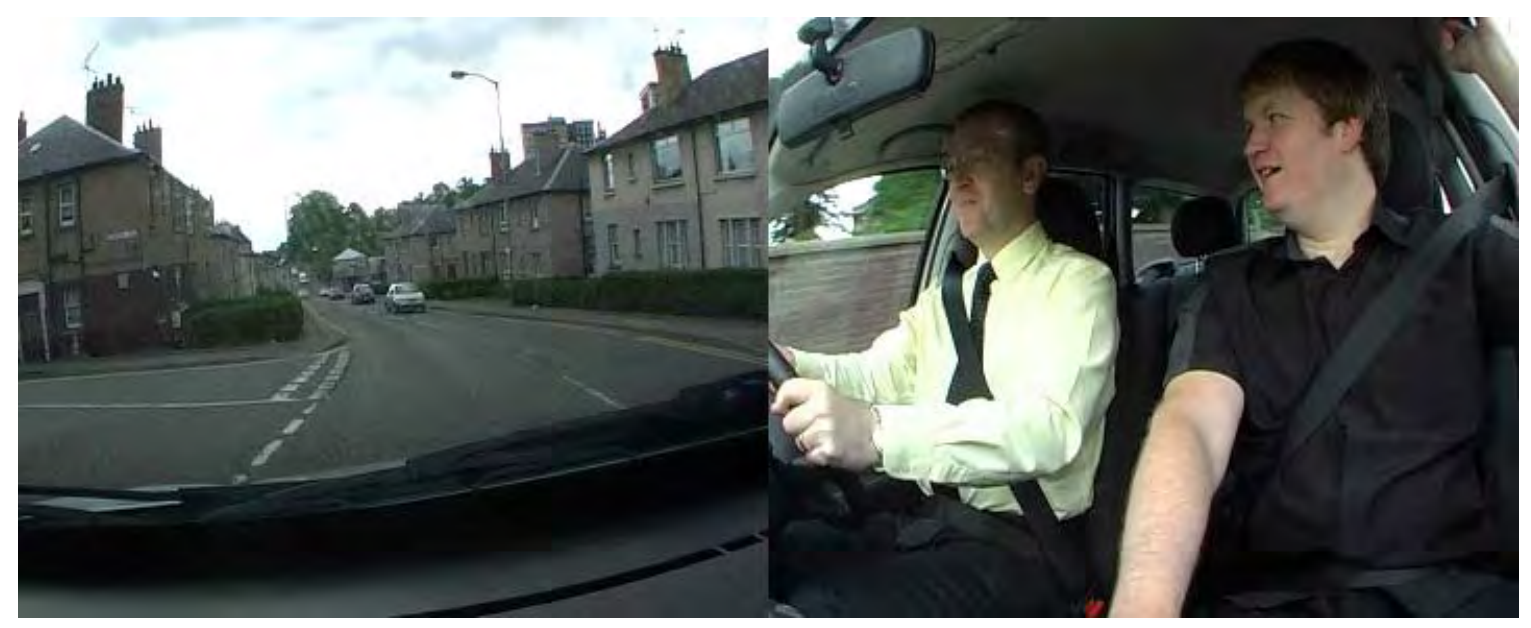

Driver: "Yeah"

Passenger: "£1.43 a mile"

Categorisations of 'driver' and 'passenger' are surely important in how this is accomplished, given that the passenger is free to look where they like, whereas drivers really ought to be watching the road and traffic ahead. Intuitively, there seems an obvious case for asymmetry between the two roles, in terms of the freedom found to look and move during conversation. That is, once the car is moving, the driver's attentions will be more closely oriented to driving than will those of the passenger. The passenger will have greater license to turn to face to the driver, use hands to gesticulate and so on. Somewhat surprisingly our video clips did not demonstrate this sort of asymmetry. What we found were solutions to the driver's dilemma - they would look in punctual rapid glances across at the passenger when and if they could fit it in amongst 
watching the road ahead. There seemed to be a commitment to retaining parity and similarity in the mutual attendance of occupants of the car's front seats.

What we found was that for the driver and front-seat passenger there are two potential looks that go without immediate exchange or response (see Figure 6):

1. Where one looks at the other and finds their eyes fixed on the road ahead. In the passengers case they could wait a little longer to give the driver the opportunity to return their look. These are orphaned looks.

2. Interestingly there is a second recognisable look that checks on the status of the other (a "how is she getting on?" sort of look) which while not returned might be a response to the driver being agitated, stressed or delivering a story.

Regardless of their status, people travelling in the front seats of the car predominantly look out of the windows of the car. This may seem obvious but the point is that the car thereby re-arranges the geometries of our mutual monitoring in ways that can produce a different sort of togetherness. In the video we found some people being intimate and others less so, and that much of this was bound up with catching one another's glances. The timeliness involved is reminiscent of laughter and its relationship to intimacy (Jefferson, Sacks, \& Schegloff, 1987), the other's glance being so much harder to catch when they flit back and forth like mayflies in the car. Quite why the balance between driver and passenger's mutual monitoring might be maintained in difficult circumstance becomes more apparent if we consider what sort of social object is built when, and if, the passenger looks at the driver for much greater lengths of time. The passenger is 'staring', 'scrutinising' or 'monitoring' the driver. Of course, there are acceptable ways of a passenger looking at a driver under other sorts of category-generated responsibilities such as where one is a driving instructor and the other a pupil. In the car, for family members, colleagues and acquaintances, the geometry of visibility most obviously resembles sitting on the sofa watching television together.

Under patient examination, the visibility arrangements of bodies between front and backseats becomes apparent as a further oddity of the car as a space for friends, family and colleagues speaking to one another. Conversations between front seats and back seats of the car are versed through a spatial arrangement that has those in the rear seats looking at the backs of the heads of those in the front (Figure 5). Even worse those seated in the front are not positioned to see those in the back at all, unless by uncomfortably craning their necks, or by customised use of the small rear-view mirror and make-up mirror (and eye-to-eye contact using the rear-view mirror was entirely absent from our corpus, though use of the mirror by parents and carers to monitor children in the back was not). Perhaps it is only the taxi driver who is willing to persist with this mirror-eye contact since they are never normally joined in the front seat.

Figure 8 . 


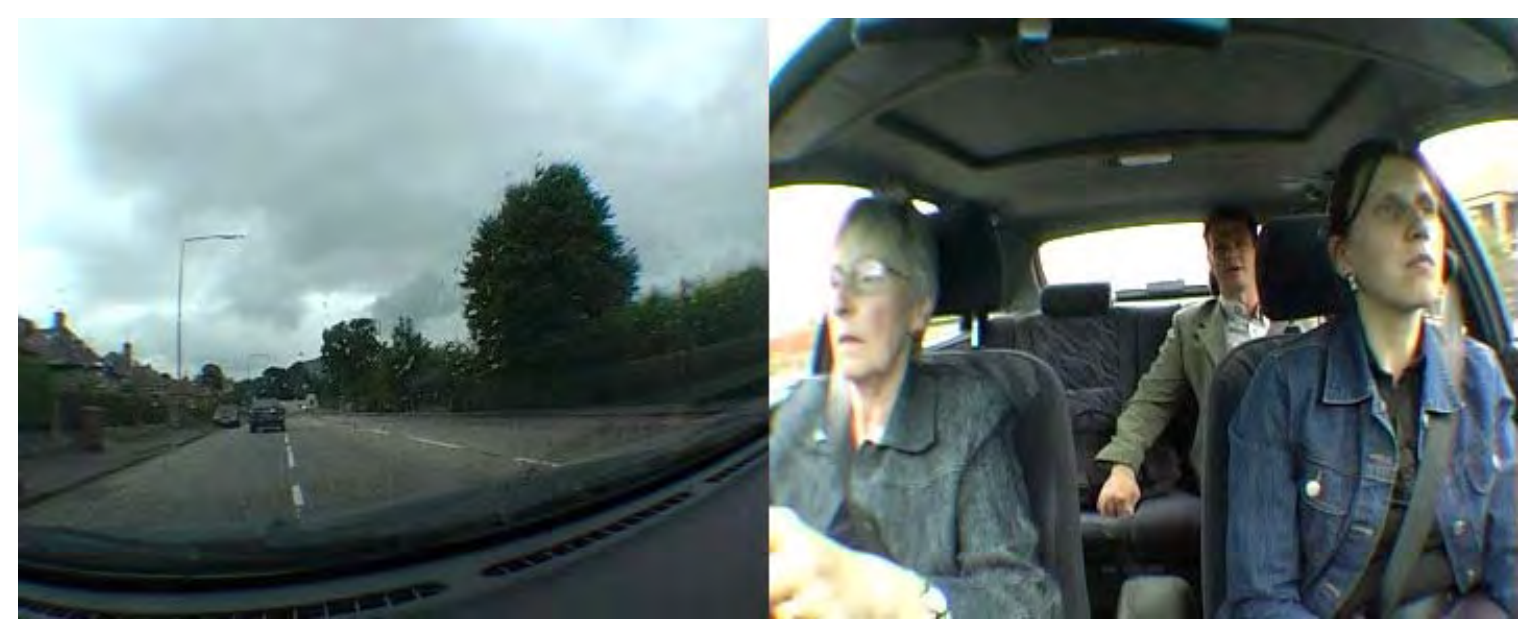

Backseat Passenger: ((moves head which becomes visible in gap between seats)) ... new lease of life shortly before they die

Driver: $\quad$ Yes it can be strange [can't it]

BP: $\quad$ [You hear] that I mean you hear that with people that suffer from

cancer

Specific variations in visibility accepted, the car's basic layout also does much to separate the front seats from the back. This social arrangement is amplified by levels of ambient road noise during travel so that on motorways conversation between the front and back is almost impossible. On the other hand driving in the city at $15 \mathrm{mph}$, it is quiet enough that mum and grandmother can be with the children in the rear, even if they are not fully involved in their talk (as in figure 6). More accurately, those in the front are an audience to the conversations of children, friends or colleagues in the rear, but an audience with their back turned. One obvious consequence of this back-to-front set-up is that speakers in the rear find it hard to monitor whether those in the front are responding/listening to what is being said. And when a young family travels, conventionally, those occupying the rear seats are children.

Children's place in the car merits specific consideration, certainly more detailed than can be attempted here. As passengers, they will find themselves cut-off by the front seat back seat geography. Smaller bodies and voices create a whole extra set of conversational limitations. The view offered by the back seat cameras (see Figure 3, left frame) is especially instructive in this respect: when both front seats are occupied, what the child sees directly ahead is the back of the seat and a bit of a head, and, by a diagonal line of sight, an oblique facial profile. Moreover, children's physical 'otherness' requires the paraphernalia of the extra obstructions to leaning forward or around of child seats.

Despite limits as to what each row of seats in the car can see, those seated in the front can and do make gestures that are directed to those behind. In several clips, motherdrivers or mother-passengers twist their torsoes to look over their shoulders to reprimand or monitor children in the back (Figure $6 \& 7$ ). As we have noted, those in the front would require eyes in the back of their heads to mutually monitor or exchange glances with those in the back. Instead turns of the head, which do not go all the round to actually looking over the should, are used as visible gestures in direct response to, or as a means to monitor, what is being said and done in the back. Effective display of 
reciprocal gestures is harder for those in the back since those seated in the front cannot be expected to see them. We find them leaning into the middle of the bench seat at the back (Figure 5), relying on audible interventions. In these ways and many others, conversation is situated in the ordinary architectural fabric of the car. The ways in which conversation is seen and heard depends on where you are in the vehicle. Consequently, seat position is a seen though overlooked aspect of the organisation of conversations in cars.

\section{The bospitality of car sharers}

Establishing, fostering and repairing car sharing is no small task as we found revealed in video fragments of these accidental fellow travellers. For commuters, sharing the journey and the space of the vehicle can be a job in itself, all before paid work actually begins. In bracketed journeys, at the opening and closing of the working day, there emerge, exist and end relationships of host and guest, driver and passenger. Keeping this pairing a felicitous one requires a different sort of care and maintenance than the vehicle that transports them. Much like Balch's (2005) study of car sharing, we found these special forms of acquaintanceship worthy of close scrutiny, not least because if the pooling of privately owned cars is to be encouraged, we have to understand what makes undertaking it appear such a perilous obligation. Sharing a car journey to work (or elsewhere) has the unusual responsibility toward one another which we usually associate with those forms of co-habitation such as sharing a flat or an office. Although not quite a building, the car is, in some senses, a room that moves around, with, in the other sense of the word, very little living room inside.

Figure 9

Driver:
$\begin{gathered}\text { I was feeling really sorry for these Muslim families in Leeds, I mean } \\ \text { [imagine] } \\ + \\ \text { Passenger: }\end{gathered}$
$[\mathrm{Mbm}]$

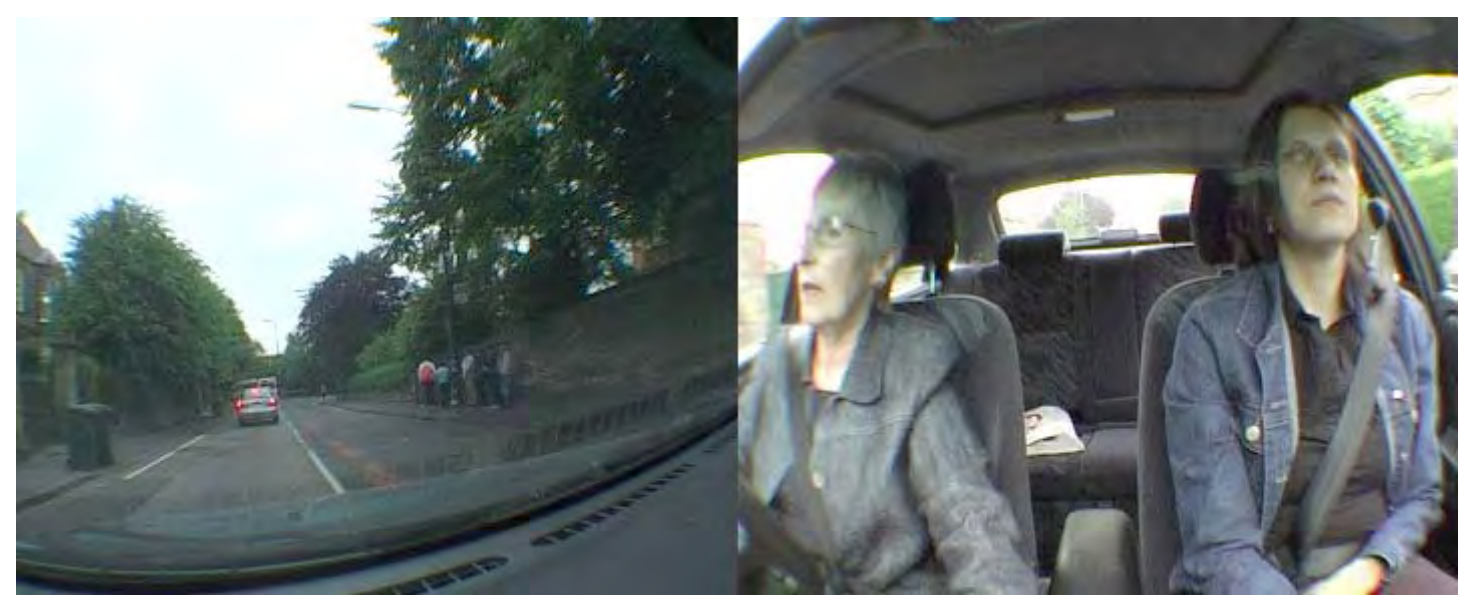

Driver: discovering that your son had been, you know, away learning to be a terrorist and you thought he was doing some extra religious ((change gear and slow down)) 
Driver: $\quad$ But was doing, they were doing religious instruction and things like that 'n' (1.0) you know those guys ((looks across to passenger))

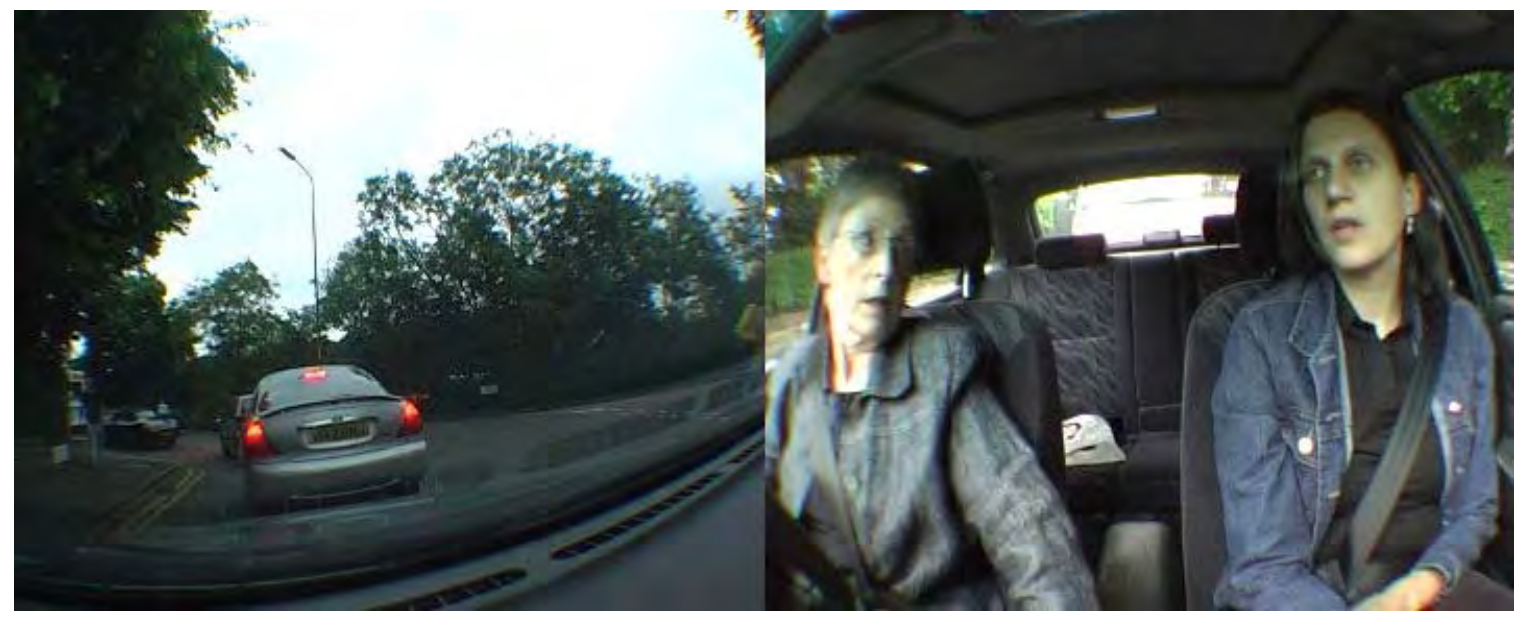

Passenger: Yeah, how are they so sure about it, I never [really, you know]

Driver:

[because they have been abroad]

bave been abroad and on, on training

Passenger: $\quad$ Ob I see

However high the design standards, by its dimensions the car remains a small space and its confinement and proximity exert considerable pressure to speak. It is a particular type of private space where others are invited to be transported from one place to another, one that it is notably unlike public transport where the social expectation of speech is reduced to the point of polite indifference. Car pooling is an arrangement that at least in the UK draws upon, even as it threatens to erase or confuse, the private-public space distinction.

To take the measure of this kind of arrangement it is useful to ask, how are driving and passengering combined with 'hosting' and to 'guesting' in a commuting relationship? In limited ways, the driver, who is ordinarily the owner of the car, receives the passenger (in that they are in the car first) and becomes responsible for the welfare and comfort of their guest. From day to day, they may (or may not) offer a welcome to their vehicle, ask if their passenger is comfortable and so on. For whoever is the driver that day (many car sharers swap around) they have some proprietary control over what are acceptable habits for shared travel. By its design for a driver, by themselves, to operate it (in contrast to large ships or airliners) the persons occupying the passenger seat might regard it polite and proper to ask before touching or altering cabin controls. It is not only by its physical properties, technical capacities and adjustable micro-climate that cars can be "hosted". Drivers are responsible for the entertainment, which is usually and simply the radio/CD player. They choose the radio station and it is their CDs that are slotted into the slim buckets at the bottom of the doors.

For the passenger who becomes a guest in a car sharing relationship they ought to reciprocate in some manner. Generally - though not always - by not only reversing the role regularly but by being a welcome guest. However in some of the commuting cars we 
studied, the passengers were always passengers as they either did not drive at all or drove only as far as their host's house before transferring to their car. In this less reciprocal situation what constitutes a good guest, or good car pool passenger, is all the more crucial to the arrangement of sharing. Different kinds of conversational and spatial formation matter here. For guest as much as host hospitality was concretised in inquiring after and listening to personal news, stories and views (see also (Balch, 2005)). In some cars acquaintanceships appear assured and relaxed, even well-tuned the host guest pairing seemingly dissolves, or perhaps its better to say, grows into easy camaraderie. However amid the distractions of traffic, misunderstandings and misheard conversation required frequent repair and consequently we found that guest-host pairings were at times precarious and tense. Car sharing sometimes involves three or more people with changing numbers present depending on holidays, mis-matching logistics, swaps between cars and therefore, who assumes the role of host. In the longer run the division of labour can become complex in terms of who did what for whom, who owes what to whom and who ought to be driving their car each week. Thus while guest and host are background categories to driver and passenger they do not cause car sharing patterns - they are resources for moral assessment of each person's conduct during the journey (Sherlock, 2001).

Importantly, lift-giving like gift-giving is an anticipative arrangement. We found car sharers planning ahead, trying to keep to an ongoing worked-out timetable of pick-up and drop off points, and often must financially account for what they are doing. Folded into seemingly logistical concerns were the anticipative assumptions. Outside of the daily concerns of the next lift, quite what and how various topics were discussed, such as terrorism in figure 9, were oriented to the future journeys together. For the persons we studied, who liked to avoid confrontation, carpool talk was not so much circumscribed or curtailed, rather, it was an on-going search for "safe" topics (H. Sacks, 1992) such as, classically, 'the weather'. Their ways of speaking were characterized by open-ended questions, tentative, rounded-off sorts of answer and, from time to time, quietly bitten tongues. Alternatively, for those pairs of drivers and passengers who liked nothing more than a heated debate the car was the perfect setting to try and start one up. In one vehicle the pairing involved a happily opinionated driver and her not quite so content passenger who, while she surely had more opinions than she expressed, found ways to defer, or passively receive (without wholly accepting) the opinions of the driver.

Without trying to make the experience sound too painful, car sharers tolerate one another's company, safe in the knowledge of the common good, or savings, they are making. In fact there are certain matters they can raise with car share acquaintance precisely because they are not part of their friendship network. Matters that might compromise loyalties or that might benefit from a disengaged perspective which owes no loyalty to shared friends. Accommodating a hitch-hiker provides a useful point of comparison with car-sharing. Picking up a hitch-hiker (today an almost forgotten practice) is a one-off act of hospitality that does not undermine the driver's freedoms. Should the shared journey be found boring, uncomfortable or even scary, it does not have to be repeated. In contrast, a driver agreeing to a car sharing arrangement opens herself up to a regular commitment, one that has, at the very least, the potential for the awkwardness small talk and the even greater awkwardness of big talk. Yet that is also the exciting potential of car-sharing, your passengers or drivers really might be, if not fellow travellers, equally as worthwhile sources of stimulation, valuable stories, advice and more. 


\section{The uses of a car journey}

During a journey, the world around the car moves toward and past it, in and out of it, and is more or less present in conversation. Sometimes the world around the car forms part of the responses of those sitting inside (either in talk or gesture), other times it is ignored. For its co-occupants, the car provides a shared intentional space. They have a common project in mind, of leaving somewhere, travelling without accident, injury or serious dispute, and arriving somewhere else.

There are temporal dimensions to the activities undertaken in each and every mutually intended journey. To rehearse an old travelling aphorism, each journey must have a beginning, middle and an end. These analysable, recognisable and quite mundane features of the journey provide an organisational structure that frames what could possibly be accomplished during a trip by car. On the well-trodden paths recorded on the videos the driver and passengers initiated talk about a particular matter with a shared sense of how long they had to complete their conversation. They were not conversing in general', they were always doing something specific like delivering news, telling troubles (fig. 11) or commenting on the conditions of the roads etc. When initiating requests, long or short stories, sharing a joke and so on, they knew how it would likely fit the stage of the journey.

Figure 11

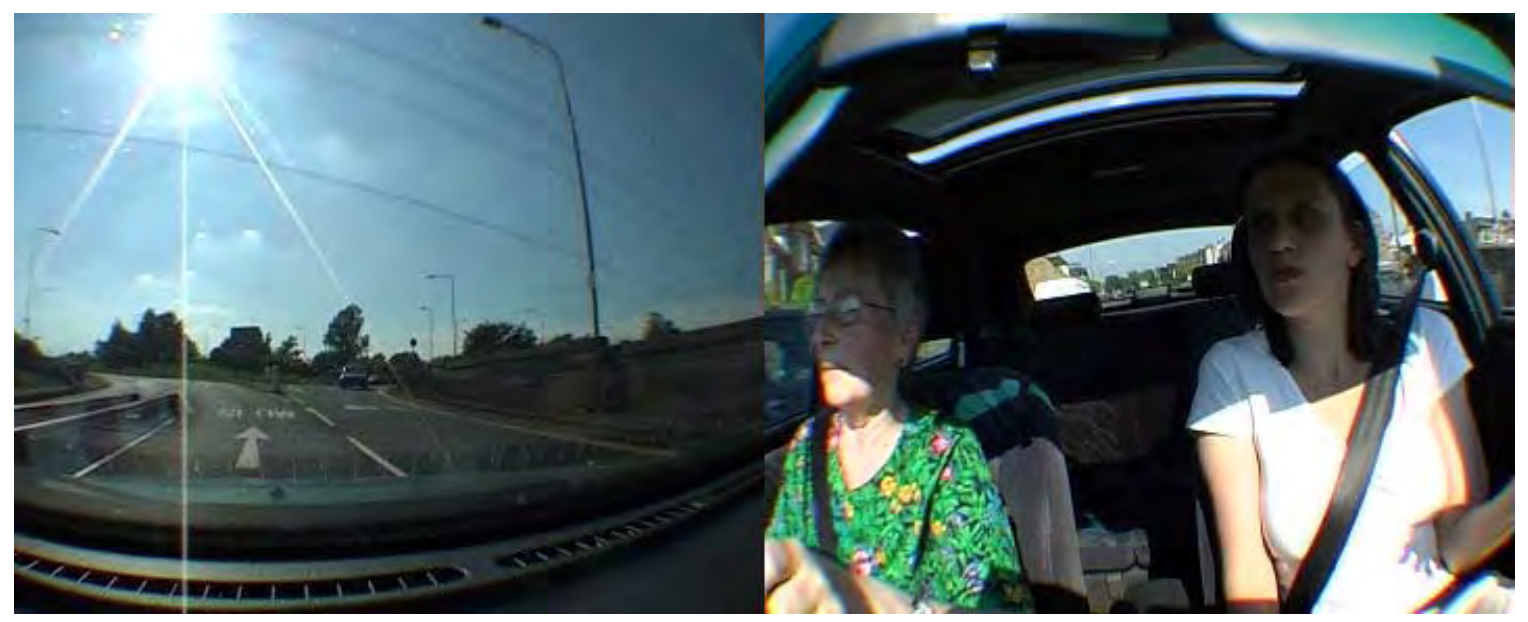

Passenger: I I was overhearing a conversation and I butted into the conversation so she was right to tell me that, you know, I shouldn't have. But the way she said it, it was just like, you know "why do you think you're talking to me now!" And I just said "well okay you know I just thought I'd help" and then went away. And you know the way she said it, it was really, you know, sticking a knife in your heart and turning it round

Driver: $\quad H m$

Passenger: And ehm (1.0) I then went to write an email because I thought, you know, she obviously was not happy so I'll have to apologise and I wasn't going to speak to her because I thought I would burst into tears or something. So ubm I just wrote an email saying, you know, I'm really sorry I interrupted your conversation with John, trying to help but obviously didn't help so I'll never do it again, 
you know. Sorry. (1.0) But you know, she did not get the email and she came into my room and said "that's not going to happen again. You're never going to do this again. It can't happen" and you know, "Be careful!" And I was like "yes okay. That's fine" And after that I felt really bad.

Driver:

I'm sure you would.

Commutes and school runs share qualities of repetitiveness and repetition: as each journey unfolds it draws upon the habits, routes and conversations of the however many journeys have happened previously and is in anticipation of those that lie in the future. For instance the troubles told in figure 11 on the journey home were taken up again the next morning, after the passenger had spoken to her husband. Taken up with her colleague and driver to plan how and whether she ought to make a complaint about their shared colleague at work.

Our footage of commuters who travelled the same route every day showed this awareness in action. Passing by known-in-common features commuters projected that there were five or ten minutes left until arriving at work or home or, more subtly, at sections of the road likely to demand the driver's attention. For instance, certain kinds of question - sometimes open, sometimes closed - were posed at appropriate slots for being responded to by the other in relation to what stage they were in the journey. In the middle of the school run one child artfully discussed owning a dog in a hypothetical manner with her mother, switching to serious pleading only as they approached a stopoff to pick up another child. 'So, how was your weekend?' was not asked just as the commuters turned into the office car park, though 'what time are you leaving today?' was. Of course, not all journeys are commutes or school runs with a known, anticipatable course. In leisure time, car travellers explore new areas and sometimes just go for a run. The open-endedness of these journeys means they can last longer than anything the travellers could possibly plan to talk about. 


\section{Closing Remarks}

In traditional economic models journey time is formulated in terms of cost and is, broadly speaking, 'lost' (Lyons \& Urry, 2005). Regardless of who is with us, travel time is time spent, it is not time savoured, hated, shared, enjoyed or recollected. The diverse social activities we have sketched out here that occur during ordinary journeys are, therefore, to a monetary way of thinking of little or no value. By documenting the everyday activities of people travelling together as families, colleagues or friends as we have done in this article what we hope is becoming apparent is that the time we pass in the car is of value in other significant ways beyond, or parallel to, the necessary reductions of traditional economic models.

We hope from the article it is apparent that what happens in the space of the car should not be seen in isolation from other places. Given that the 'Habitable Cars' project concentrates on the journey, and, in methodological terms, only asked its subjects to record while in the car, it has that located and partial view of how travelling together is organised. From many quarters in the social sciences we have come to understand that there are only ever located and partial views of society (Amin \& Thrift, 2002; Latour, 2005). Moreover we would argue, in tune with others (Urry, 2000), that there are all manner of social phenomena occurring during the journey that are worthy of the attention of those interested in how mobile life happens while in motion. The clips we have commented on here, to an extent, show the car as a translation and displacement of the office or the domestic spaces which the drivers and passengers also shared. For instance we have two colleagues from a financial services company talking work on the commute - the family units adapting aspects of the life they lead in houses, schools and parks into the car. In these ways, what might be thought of as the travellers' lives 'outside' the journey are thoroughly folded into it. Given the particularities of cars as small scale architectural spaces, they offer occasions which disrupt and demand the re-assembly of whatever the social relations and the politics of the office and the house are. Inside centrally locked doors there are captive audiences and speakers - sedentary yet occupied bodies, a chance for intimate yet interrupted exchange. The child asking parents for things or asking awkward questions; the office workers talking through an issue.

Through the seven thematic sections in the article we have re-examined, if only partially and tentatively, the value and practical logics of a number the daily activities that take place within it.

1. Against the conceptualisation of the driver as a lone Cartesian self contemplating an external road, driving can also be understood as a socially ordered activity with the front-seat passenger playing their part in particular tasks.

2. Conversations that we typically imagine taking place over dinner or breakfast tables have been shifted into the space of the car. While the car does not determine what can be said there, in making conversation in its unusual setting we have different resources and problems.

3. Relatedly, by virtue of the pause-full, interruptible conversations we have in the car, while much of it is trivial, equally it can be a good place for some of our most serious conversations on matters of life, love and death.

4. For families, in particular, the car is a setting where, with parents and/or carers and children assembled tightly together, parents learn about their children and children learn from their parents. For colleagues too, the car serves as a place for 
advice-giving, counselling and swapping tips, hints, war stories and tricks of their trade.

5. Specific arrangements of social visibility are manifest in the car in terms of how any vehicle is seen by those outside it, and how those inside it are able to watch, monitor and display what they are doing to one another

6. For commuters sharing a car brings them into a relationship of responsibility and care for one another that is located somewhere between friendship, neighbourliness, house-sharing and office-sharing. They are 'car-mates' and with this new form of social relationship come new expectation and obligations toward one another.

7. Just as the car offers us resource as a particular sort of space, so the car journey has features which are realised and utilised by persons, be they colleagues, families or friends travelling together. The idea of the 'Sunday drive' is the beginning of such a notion.

Quite how these initial sketches are detailed and elaborated will be the concern of future papers that will closely analyse the video fragments that we have only been able to cite in passing in this article. Nevertheless we hope this article has served to open up the interior of the car, as it journeys, as a place of import for society and substantial interest for social science investigations. 
Appendix - Transcription symbols

[hi]

$+\quad$ overlapping speech

[hello]

(3.0) pauses in seconds

it was today speaker emphasis

((hand goes up)) non-verbal actions

$=\quad$ latched speech

(sauce/source) uncertain transcription of words 


\section{BIBLIOGRAPHY}

Amin, A., \& Thrift, N. (2002). Cities: Re-imagining the Urban. Cambridge: Polity.

Appleyard, D., Lynch, K., \& Myer, J. R. (1964). The View from the Road. London: MIT Press.

Balch, S. (2005). 'Doing acquaintanceship', the practical accomplishment of being a car sharer. Unpublished Masters, University College London, London.

Bjelic, D. (2004). Galileo's Pendulum: science, sexuality and the body-instrument link. New York: State University of New York Press.

Brown, B. A. T., Green, N., \& Harper, R. (Eds.). (2002). Wireless World : Social and Interactional Aspects of the Mobile Age. London: Springer.

Bull, M. (2005). Automobility and the power of sound. Theory, Culture \& Society, 21(4-5), 243-260.

Cresswell, T. (2006). On the move. London: Routledge.

Featherstone, M., Thrift, N., \& Urry, J. (Eds.). (2005). Automobilities. London: Sage, TCS.

Garfinkel, H. (2002). Ethnomethodology's Program, Working Out Durkheim's Aphorism. New York: Rowman \& Littlefield Publishers.

Heath, C. (1997). Analysing work activities in face to face interaction using video. In D. Silverman (Ed.), Qualitative Methods (pp. 183-200). London: Sage.

Hester, S., \& Francis, D. (2003). Analysing visually available mundane order: a walk to the supermarket. Visual Studies, 18(1), 36-46.

Hopper, R. (1992). Telephone Conversation. Bloomington: Indiana University Press.

Jefferson, G., Sacks, H., \& Schegloff, E. A. (1987). Notes on laughter in the pursuit of intimacy. In G. Button \& J. R. E. Lee (Eds.), Talk and social organisation (pp. 152205). Clevedon: Multilingual Matters.

Juhlin, O. (2005). Beyond just getting there - the interactive road. receiver, 12, www.receiver.vodafone.com/12/articles/pdf/12 05.pdf.

Katz, J. (1999). How emotions work. London: University of Chicago Press.

Larsen, J., Urry, J., \& Axhausen. (2006). Social networks and future mobilities. Report to the UK Department for Transport. Lancaster \& Zurich: Lancaster University \& IVT, ETH.

Latour, B. (2005). Reassembling the social: an introduction to actor-network theory. Oxford: Oxford University Press.

Latour, B., \& Callon, M. (1981). Unscrewing the Big Leviathan; or How Actors Macrostructure Reality, and How Sociologists Help Them To Do So? In K. Knorr \& A. Cicuourel (Eds.), Advances in Social Theory and Methodology (pp. 277303). London: Routledge and Kegan Paul.

Laurier, E. (2005). Searching for a parking space. Intellectica, 41-42(2-3), 101-115.

Livingston, E. (1987). Making Sense of Ethnomethodology. London: Routledge \& Kegan Paul. Lynch, K. (1960). Image of the City. London: MIT Press.

Lynch, M. (1993). Scientific practice and ordinary action: ethnomethodology and social studies of science. Cambridge: Cambridge University Press.

Lynch, M. (1999). Silence in Context: Ethnomethodology and Social Theory. Human Studies, 22(2), 211-233.

Lynch, M. (2002). From naturally occurring data to naturally organized ordinary activities: comment on Speer. Discourse Studies, 4(4), 531-537.

Lyons, G., \& Urry, J. (2005). Travel time use in the information age. Transportation Research Part A, 39, 257-276.

Maynard, D. W. (2003). Bad News, Good News. Conversational Order in Everyday Talke and Clinical Settings. Chicago: University of Chiacago Press. 
Merriman, P. (2006). 'Mirror, signal, manoeuvre': assembling and governing the motorway driver in late fifties Britain. In S. Böhm, C. Jones, C. Land \& M. Paterson (Eds.), (pp. 75-92). London: Sociological Review.

Michael, M. (1998). Co(a)agency and the Car: Attributing Agency in the Case of the 'Road Rage'. In B. Brenna, J. Law \& I. Moser (Eds.), Machines, Agency and Desire (pp. 125-141). Oslo: TVM.

Michael, M. (2000). Reconnecting Culture, Technology and Nature, Routledge. London: Routledge.

Miller, D. (Ed.). (2001). Car Cultures. Oxford: Berg.

Mondada, L. (2004). EMIC - Espace, Mobilite, Interaction, Corps. Lyons: Univ. Lyon2 \& CNRS \& PSA-Peugot.

Mondada, L. (forthcoming). Video recording as the preservation of fundamental features for analysis. In Schnettler (Ed.), Video Analysis. Oxford: ...

Perry, M., \& Brodie, J. (2005 ). Virtually connected, practically mobile. In Andriesson \& Vartiainen (Eds.), Mobile Virtual Work: a new paradigm (pp. 97-127). Berlin: Springer.

Pica, D., Sorenson, C., \& Allen, D. (2004). On Mobility and Context of Work: Exploring Mobile Police Work. Paper presented at the 37th Annual Hawaii International Conference on System Sciences, Hawaii.

Ryave, A. L., \& Schenkein, J. N. (1974). Notes on the Art of Walking. In R. Turner (Ed.), Ethnomethodology (pp. 265-274). Harmondsworth: Penguin.

Ryle, G. (1949). The Concept of Mind. London: Hutchinson.

Sacks, H. (1984). On doing being ordinary. In J. M. Atkinson \& J. C. Heritage (Eds.), Structures of Social Action (pp. 413-429). Cambridge: Cambridge University Press.

Sacks, H. (1992). Lectures on Conversation, Vol. 2. Oxford: Blackwell.

Schegloff, E. A., \& Sacks, H. (1973). Opening up closings*. Semiotica, 8(4), 289-327.

Sheller, M. (2005). Automotive Emotions: Feeling the Car. Theory, Culture \& Society, 21(4/5), 221-242.

Sheller, M., \& Urry, J. (2003). The City and the Car. In A. Root (Ed.), Delivering Sustainable Transport, a social science perspective (pp. 171-189). Oxford: Pergamon.

Shove, E. (2003). Rushing around: coordination, mobility and inequality. online paper, Department of Sociology, http://www.comp.lancs.ac.uk/sociology/soc120es.htm.

Taylor, A. S., \& Swan, L. (2005). Artful systems in the home. Paper presented at the Conference Name|. Retrieved Access Date|. from URL|.

Thrift, N. (2004). Driving in the City. Theory, Culture \& Society, in press, NYP.

Ulleberg, P. (2004). Social influence from the back-seat: factors related to adolescent passengers. Transportation Research Part F, 7, 17-30.

Urry, J. (1999). Automotility, Car Culture and Weightless Travel. Department of Sociology, Lancaster University, bttp:/ / www.comp.lancaster.ac.uk/sociology/soc008ju.btml.

Urry, J. (2000). Sociology beyond Societies. Mobilities for the Twenty-First Century. London: Routledge.

Urry, J. (2002). Inhabiting the Car. http://www.comp.lancs.ac.uk/sociology/papers/UrryInhabiting-the-Car.pdf

: Department of Sociology, Lancaster University, Lancaster LA1 4YN, UK.

Venturi, R., Brown, D.S., \& Izenour, S. (1988). Learning From Las Vegas (revised edition). London: MIT Press.

Watson, R. (1999). Driving in Forests and Mountains : A Pure and Applied Ethnography. Ethnographic Studies, 3, 50-60.

Watts, L. (2005). The art of train travel or how to tell a story of people, places and technical paraphernalia. online paper, Department of Sociology, Lancaster, 
http://www.lancs.ac.uk/wattslj/postgrad/downloads/watts artoftraintravel apri 12005.htm.

Weilenmann, A. (2003). Doing mobility. Unpublished Doctoral, G öteborg University, G öteborg. 